\title{
A numerical approach to the energy efficiency of laser welding
}

\author{
G. Pastras $^{1,2}$ • A. Fysikopoulos ${ }^{1,3}$ • G. Chryssolouris ${ }^{1}$
}

Received: 12 October 2016 / Accepted: 20 February 2017 / Published online: 9 March 2017

(C) The Author(s) 2017. This article is published with open access at Springerlink.com

\begin{abstract}
The industrial sector is increasingly concerned with energy consumption, due to the environmental burden and increased cost. An action plan requires the study of energy efficiency in manufacturing processes, especially energyintensive processes. The energy consumption, during the assembly, plays a significant role on the product's final energy and eco-evaluation. In this paper, there is a presentation of an in-depth study of the energy efficiency of joining processes. The laser welding process is also discussed in detail, since it has been an increasingly indispensable part of competitive manufacturing throughout the world, and it is a thermal process with relatively low energy efficiency. Important outcomes, regarding the dependence of energy efficiency and weld pool geometry on process parameters, have been derived.
\end{abstract}

Keywords Energy efficiency $\cdot$ Laser welding $\cdot$ Weld pool geometry $\cdot$ Joining process $\cdot$ Sustainable manufacturing

\section{Introduction}

Laser processing has been an increasingly indispensable part of competitive manufacturing throughout the world [1-5].

G. Chryssolouris

xrisol@lms.mech.upatras.gr

1 Laboratory for Manufacturing Systems and Automation, Department of Mechanical Engineering and Aeronautics, University of Patras, 26500 Patras, Greece

2 Department of Physics, School of Applied Mathematics and Physical Sciences, National Technical University, 15780 Athens, Greece

3 Automation Systems - Materials \& Process Technologies, COMAU SpA, Via Rivalta 49, 10095 Grugliasco, TO, Italy
Specifically, laser welding (LW) [6, 7] has been widely used in the automotive, aerospace, electronics, and heavy manufacturing industries to join a variety of materials. In the last few years, a new laser process, the remote laser welding (RLW) has emerged. RLW [8, 9] has been developed and implemented to improve the productivity and flexibility of conventional LW. In the automotive industry, high-power lasers are used for welding many components, such as transmissions, catalytic converters, exhaust systems, closures, and tailor-welded blanks [10, 11].

Manufacturing the products of the future by incorporating economic, social, and environmental sustainability is a major challenge for today's manufacturing industry. The need towards sustainable manufacturing has been more imminent than ever before. State regulations, along with the increasing energy prices, exert a new pressure on manufacturing enterprises. Thus, the industrial sector has to reduce energy consumption both for cost saving and environmental friendliness, in its attempt to find new flexible ways to produce "more with less" [12] and furthermore evolve from the strategy "maximum gain from minimum capital" to "maximum gain from minimum resources" [13].

The investigation of the manufacturing processes, from an energy point of view, indicates that only a small fraction of the energy input actually adds value to the final product [14] and an amount of $20-40 \%$ of the energy used in industry is of no added value [15]. Furthermore, the largest amount of energy is used for the creation of stable process conditions and peripheral functions $[16,17]$.

Although the energy spent on the process itself is a small percentage of the overall energy consumption [19], the recently developed systematic approaches for the improvement of energy efficiency in manufacturing systems [18] show that process models, focusing on the process itself, along with the specific machine peripherals consumption and their 
dependence on the process variables, are required for the realization of a holistic approach. For the optimization of energy efficiency, the determination of a large set of process parameters is required. The study of the processes is considered necessary for a number of reasons $[14,18]$ :

- The study of the processes provides the deeper possible understanding of the energy transformations that take place during the manufacturing process.

- Simple analytical models that lead to qualitative and quantitative results, adaptable to a wide range of applications, may be applied.

- Although the energy spent at process level is minor, an appropriate selection of process variables may also alter the consumption of machine peripherals that correspond to a larger percentage of energy consumption. As an example, the consumption of a cooling unit depends on the processing speed [16].

- Processing time is a function of the process variables. Thus, the selection of appropriate process parameters has consequences for both the machine peripherals' consumptions (machine level) and the production planning (line and factory levels).

- Non-conventional processes, allowing space for significant energy gains at process level, have not been adequately studied.

The above points clarify the fact that a complete analysis, addressing the problem of energy efficiency maximization, requires process modelling, focusing on the energy efficiency, not only through the description of the energy consumption at process level, as a function of the process variables, but also of other process aspects, such as the processing time. However, this subject has limited presence in literature [14] especially for the nonconventional processes [20]. Indicatively, regarding the conventional process, Draganescu et al. [21] have related the use of experiments, machine tool efficiency, specific consumed energy, and consumed energy to several machining variables of a milling process. Fysikopoulos et al. [22] studied the laser drilling and grooving process from an energy efficiency point of view, having neglected all other parameters and focused only on the interaction of laser beam with the material. Pastras et al. [20] have presented an analytical and numerical approach of evaporation laser drilling, towards the theoretical specification of the process parameters that maximize energy efficiency.

Regarding the LW process, a number of studies, attempting to model different welding states and various configurations, such as lap or butt welding, using either analytical [23, 24], semi-empirical, or empirical methods [25-27], have been carried out. However, none of the above deal with the energy efficiency of the laser welding process. In this paper, the LW process will be investigated under the prism of energy efficiency, along with important weld geometry key performance indicators (KPIs). This will be realized with the use of the numerical model previously developed by Pastras et al. [28].

\section{The numerical model for keyhole LW modelling}

This numerical model [28] takes into account the physics of both heat conduction and phase transitions during the process, as well as laser defocusing, while it neglects plasma formation and multiple reflections of the laser beam in the keyhole walls. The model's basic simplifying assumption is a static approach to the process; instead of a moving laser head performing a stitch, the laser head is considered being stationary, but it is "on" only for as much time as the laser interacts with a given point, at the center of the stitch, namely the spot diameter divided by the scanning speed.

The method's mathematics is a combination of finite differences, the enthalpy method, and "life and death of elements" techniques from the finite element method. Specifically, cylindrical coordinates are adopted to take advantage of the problem's rotational symmetry, while radius, depth, and time are considered discretized, as in finite difference problems. The temperature field is substituted by a three-dimensional matrix, containing the elements $T_{i j k}$, corresponding to the material's temperature at time $t_{i}=(i-1) \Delta t$, radius $r_{j}=(j-1) \Delta r$, and depth $z_{k}=(k-1) \Delta z$.

In order for phase transitions to be taken into account, another field, corresponding to the enthalpy density, is introduced. This field has to be connected to the temperature, in such a way so as for the latent heats of fusion and evaporation to be taken into account. Specifically,

$$
T(U)=\left\{\begin{array}{cc}
\frac{U}{\rho c}, & U<\rho c T_{m}, \\
T_{m}, & \rho c T_{m}<U<U_{m}, \\
\frac{U-\rho L_{f}}{\rho c}, & U_{m}<U<\rho\left(c T_{v}+L_{f}\right), \\
T_{v}, & \rho\left(c T_{v}+L_{f}\right)<U<U_{v},
\end{array}\right.
$$

where $\rho, c, T_{m}$, and $T_{v}$ are the material density, specific heat, melting temperature, and evaporation density, respectively. The quantities $U_{m}$ and $U_{v}$ are the required enthalpy densities for the melting and vaporization phase transition, respectively. They are equal to

$U_{m}=\rho\left(c T_{m}+L_{f}\right)$,

$U_{v}=\rho\left(c T_{v}+L_{f}+L_{v}\right)$, 
where $L_{f}$ and $L_{v}$ are the latent heat of fusion and evaporation, respectively. Then, the finite difference formulation of the heat equation, taking into account the latent heats, can be written as

$\frac{U_{i+1, j, k}-U_{i, j, k}}{\Delta t}=k\left(\frac{T_{i, j+1, k}-2 T_{i, j, k}+T_{i, j-1, k}}{\Delta r^{2}}+\frac{1}{r_{j}} \frac{T_{i, j+1, k}-T_{i, j, k}}{\Delta r}+\frac{T_{i, j, k+1}-2 T_{i, j, k}+T_{i, j, k-1}}{\Delta z^{2}}\right)$,

$T_{i j k}=T\left(U_{i j k}\right)$,

Equations (2.4) and (2.5) together with the appropriate boundary conditions, corresponding to the influx of energy, due to the laser beam, can be integrated time slice by time slice, providing the final solution for the temperature field.

The most significant complication that appears in this formulation is the fact that once the keyhole formation has started, several vertices of the lattice have to be removed and the boundary conditions have to be applied to different vertices and not to the $k=1$ ones. Thus, at every time slice and every radius, the first non-gaseous vertex is determined by

$b z_{i j}=\min \left\{k \mid U_{i j k}<\rho\left(c T_{v}+L_{f}+L_{v}\right)\right\}$

and the boundary conditions are applied to this vertex. The appropriate boundary condition is in the form of Eq. (2.4), with $k=b z_{i j}$ and with the addition to the right hand side of the influx of energy from the laser beam, which is determined by reflectivity, laser power, and spot size and once a keyhole has been formed by defocusing, along with the angle between the laser beam and the keyhole walls. More details are provided in [28].

This model is selected for the study of the energy efficiency of laser welding, for its simplicity, as well as the fact that it takes into consideration the major factors determining the energy losses during the process. Some indicative results of the model for the temperature field are depicted in Figs. 1 and 2. The solid lines in these figures correspond to the phase separating surfaces.

\section{Weld pool geometry}

An important outcome of the model [28] is the connection between certain weld pool geometry key performance indicators (KPIs) and the process variables. Several KPIs are used for the estimation of a laser weld's strength. The selection of the appropriate KPIs depends on the weld geometry. For lap welding, the most usual selections are (Fig. 3) as follows:

1. Weld length $(d)$

2. Penetration depth $(p)$
3. Interface width (s)

4. Top surface concavity $\left(c_{t}\right)$

5. Bottom surface concavity $\left(c_{b}\right)$ (only when full penetration is succeeded)

In the case of butt welding, the most usual selections are (Fig. 4) as follows:

1. Weld length $(d)$

2. Depth of penetration $(p)$

3. Top surface weld width $(w)$

4. Top surface concavity $\left(c_{t}\right)$

5. Bottom surface concavity $\left(c_{b}\right)$ (only when full penetration is succeeded)

In the case of lap welding, the weld strength is heavily correlated with the interface width, while for butt welding with the depth of penetration. Concavities can serve as a non-invasive monitoring measurement and at the same time, they are important for aesthetic reasons.

The model [28] can directly predict the values of these certain weld pool geometry KPIs. The penetration depth and interface width require the determination of the boundary between the solid and liquid phases, or, in other words, the melting temperature isothermal. Both of the boundaries in the vertical and radial directions should be specified; the first one for the determination of the penetration depth and the second one for the determination of the interface width. These boundaries can be calculated in a similar way as the boundaries between the liquid and gaseous states, described by Eq. (2.6), but for the time instant $t=t_{\max }$, corresponding to $i=N_{t}$. Thus,

$m z_{j}=\min \left\{k \mid U_{N_{t} j k}<U_{m}\right\}$,

$m r_{k}=\min \left\{j \mid U_{N_{t} j k}<U_{m}\right\}$.

Then, for lap welding, if the thickness of the top plate is considered equal to $d_{t}$, the penetration depth is equal to

$p=\left(m z_{1}-1\right) \Delta z-d_{t}$.

The determination of the interface width requires the radial boundary between the solid and liquid phases, as given by 

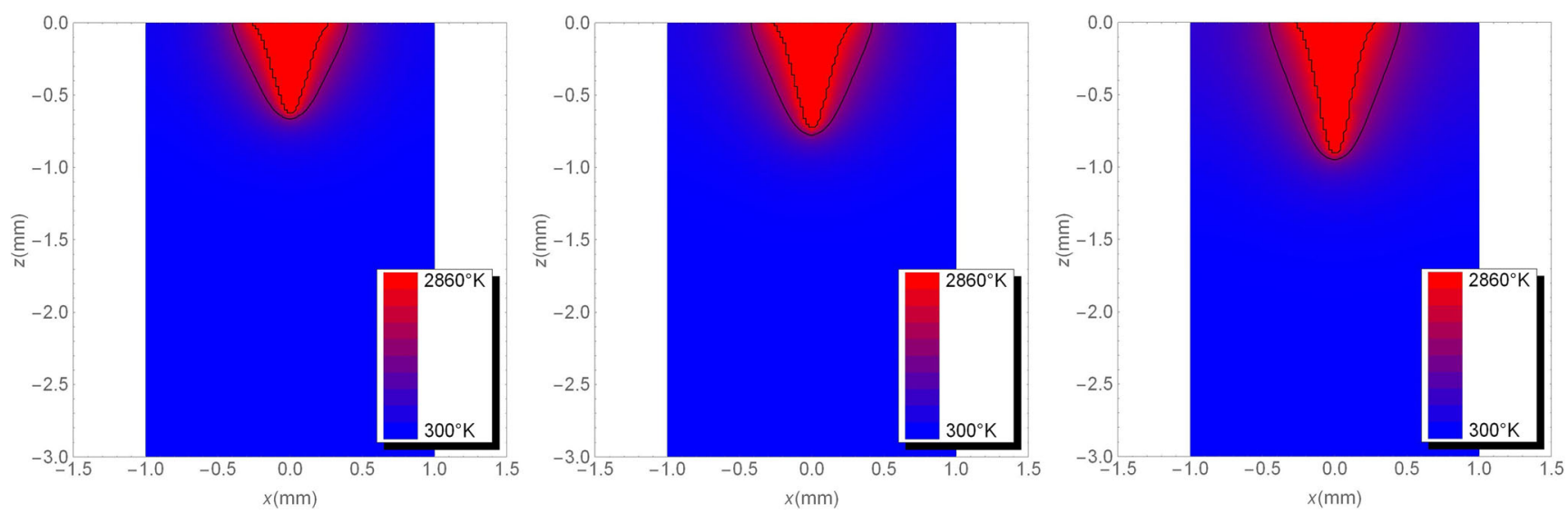

Fig. 1 Laser power $15 \mathrm{~kW}$ and scanning speeds $4 \mathrm{~m} / \mathrm{min}$ (left), $3 \mathrm{~m} / \mathrm{min}$ (center), and $2 \mathrm{~m} / \mathrm{min}$ (right)

Eq. (3.2), for $k$ being equal to the value that corresponds to the depth of the surface separating the two plates. It is possible that no $k$ corresponds exactly to this depth, with the closest value being equal to $k=$ round $\left(d_{t} / \Delta z+1\right)$. Thus, the interface width equals

$s=2\left(m r_{\text {round }\left(\frac{d_{t}}{\Delta z}+1\right)}-1\right) \Delta r$.

In this modeling approach, the concavity of the top surface is considered being the result of material loss due to evaporation. It is assumed that the weld acquires no porosity that alters the volume of the materials involved in the process. Thus, for the determination of the top concavity, it is required that the volume of the keyhole be calculated. To this effect, it suffices to calculate the boundaries between the gaseous and liquid phases in the vertical direction. Similarly to (3.1),

$v z_{j}=\min \left\{k \mid U_{N_{i j} k}<U_{v}\right\}$.
The volume can be estimated as a numerical integral. One should not forget the appropriate factors for the cylindrical coordinate system.

$V_{v}=2 \pi \Delta r^{2} \Delta z \sum_{j=1}^{N_{r}} j\left(v z_{j}-1\right)$.

Assuming that at the end of the process all molten material flows to the bottom of the keyhole, the concavity can be approximated by a cylinder with radius equal to the boundary between the solid and liquid states, at the surface of the top plate. The latter is equal to $\left(m r_{1}-1\right) \Delta r$, resulting in

$c_{t}=\frac{V_{v}}{\pi\left(m r_{1}-1\right)^{2} \Delta r^{2}}=\frac{2 \Delta z}{\left(m r_{1}-1\right)^{2}} \sum_{j=1}^{N_{r}} j\left(v z_{j}-1\right)$.

In the case of butt welding, the calculations required for the weld pool geometry KPIs are simpler. The depth of penetration is given by a formula similar
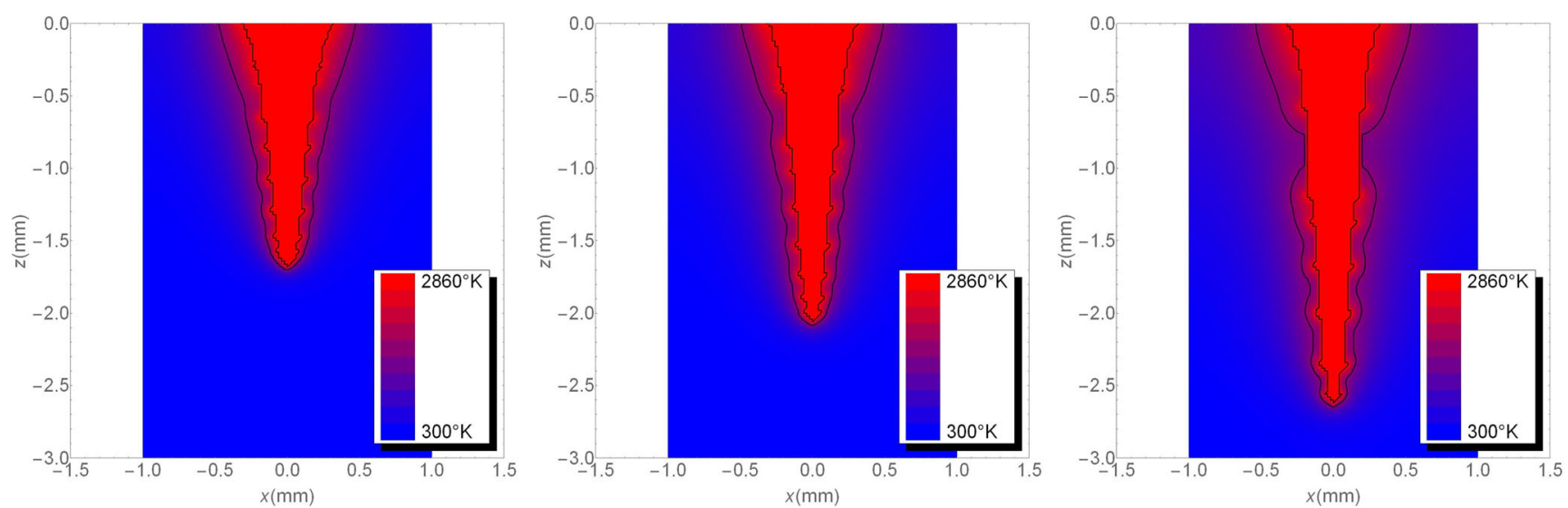

Fig. 2 Laser power $5 \mathrm{~kW}$ and scanning speeds $4 \mathrm{~m} / \mathrm{min}$ (left), $3 \mathrm{~m} / \mathrm{min}$ (center), and $2 \mathrm{~m} / \mathrm{min}$ (right) 


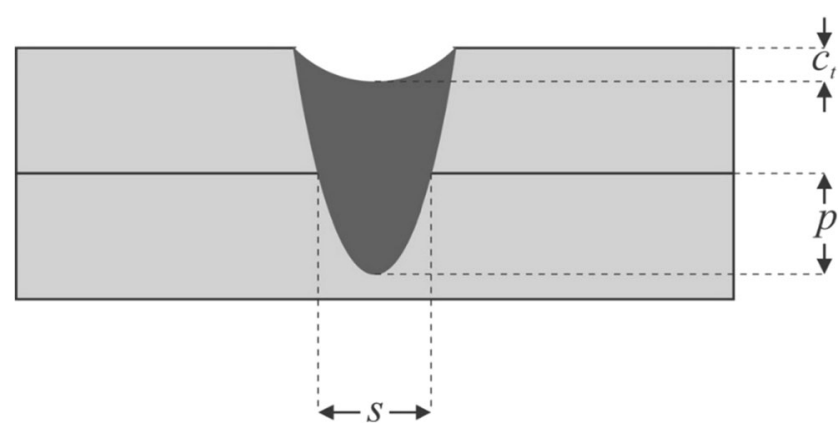

Fig. 3 Example of some of the used joint weld pool geometry KPIs in lap welding

to (3.3), but without contribution due to the top plate thickness; thus,

$p=\left(m z_{1}-1\right) \Delta z$

Similarly, the top surface weld width is given by a formula similar to (3.4), but at the workpiece surface, given by $k=1$; thus,

$w=2\left(m r_{1}-1\right) \Delta r$

Finally, the top surface concavity is given by the same expression as for lap welding, namely Eq. (3.7).

\subsection{Dependence of weld pool geometry KPIs on process variables}

The study of the dependence of the weld pool geometry KPIs on the process variables requires the model's application to a given material and laser source, for various values of the process variables. Specifically, the current study focuses on the dependence of the weld pool geometry KPIs on the laser power and the scanning speed, which have a drastic effect on the process dynamics.

For the example case studied, the material properties given in Table 1, the laser properties in Table 2, and the lattice variables in Table 3 have been used. The material properties used are typical thermal properties of mild steels and the laser properties are typical values of $\mathrm{CO}_{2}$ laser sources.

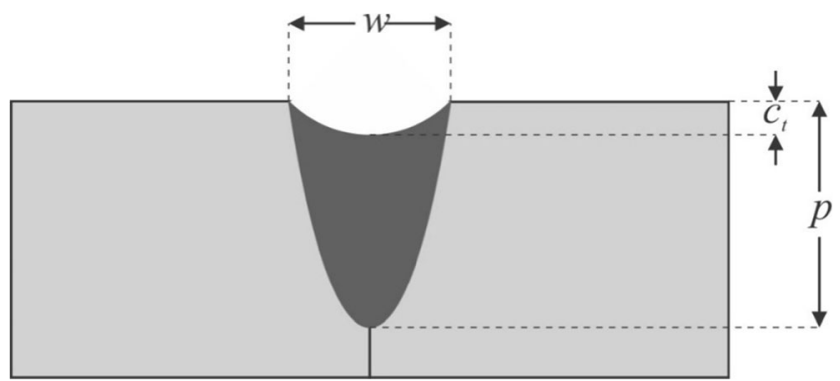

Fig. 4 Example of some of the used weld pool geometry KPIs in butt welding
Table 1 The material thermal properties used for the graphs exposing the outcome of the model

\begin{tabular}{lll}
\hline Symbol & Value & Units \\
\hline$T_{0}$ & 300 & $\mathrm{~K}$ \\
$T_{m}$ & 1680 & $\mathrm{~K}$ \\
$T_{v}$ & 2861 & $\mathrm{~K}$ \\
$k$ & 66 & $\mathrm{~W} / \mathrm{m} \mathrm{K}$ \\
$\alpha$ & $16.4 \times 10^{-6}$ & $\mathrm{~m} / \mathrm{s}^{2}$ \\
$R$ & 0.8 & - \\
$\rho$ & 7775 & $\mathrm{~kg} / \mathrm{m}^{3}$ \\
$L_{f}$ & 200 & $\mathrm{~kJ} / \mathrm{kg}$ \\
$L_{v}$ & 6090 & $\mathrm{~kJ} / \mathrm{kg}$ \\
\hline
\end{tabular}

For lap welding, it is assumed that the thickness of the top plate is equal to $d_{t}=1 \mathrm{~mm}$. The laser power is assumed to take values between 1 and $17.5 \mathrm{~kW}$, while the scanning speed between 1.5 and $12 \mathrm{~m} / \mathrm{min}$.

Figures 5 and 6 show the dependence of the penetration depth on the laser power and scanning speed in the case of lap welding. As intuitively expected, the penetration depth increases when the laser power does so or when the scanning speed decreases. It is interesting to be noted that the sensitivity of the penetration depth to the changes of the laser power is stronger at smaller scanning speeds, while the sensitivity of the penetration depth to the changes of the scanning speed is not greatly affected by the laser power.

Figures 7 and 8 show the dependence of the interface width on the scanning speed and the laser power in the case of lap welding. Similarly to the penetration depth, the interface width decreases as the scanning speed increases and increases as the laser power increases. Additionally, the curves of Fig. 7 cross the horizontal axis at the same location as the curves of Figs. 5 and 8 cross the horizontal axis, at the same points as the curves of Fig. 6. This is expected, since for each scanning speed, there is a critical laser power for the penetration of the bottom plate, which is noticeable both in the penetration depth and interface width curves. Similarly, for each laser power, there is a critical scanning speed for the penetration of the bottom plate. As shown in Figs. 5 and 7, the critical scanning speed is an increasing function of the laser power, while, as shown in Figs. 6 and 8, the critical laser power is an
Table 2 The laser variables used for the graphs exposing the outcome of the model

\begin{tabular}{lll}
\hline Symbol & Value & Units \\
\hline$r_{0}$ & 0.25 & $\mathrm{~mm}$ \\
$\delta f$ & 0 & - \\
$M$ & 1.3 & - \\
$\lambda$ & 10.6 & $\mu \mathrm{m}$ \\
$P$ & 4.0 & $\mathrm{~kW}$ \\
$v$ & 2.8 & $\mathrm{~m} / \mathrm{min}$ \\
\hline
\end{tabular}


Table 3 The lattice variables used for the graphs exposing the outcome of the model

\begin{tabular}{lll}
\hline Symbol & Value & Units \\
\hline$z_{\max }$ & 3 & $\mathrm{~mm}$ \\
$N_{z}$ & 150 & - \\
$r_{\max }$ & 1 & $\mathrm{~mm}$ \\
$N_{r}$ & 50 & - \\
$t_{\max }$ & 8 & $\mathrm{msec}$ \\
$N_{t}$ & 1600 & - \\
\hline
\end{tabular}

increasing function of the scanning speed. Finally, in Figs. 7 and 8 , it is evident that when the scanning speed or the laser power approaches the corresponding critical values, the interface width tends to zero at a very steep rate, unlike the penetration depth, as shown in Figs. 5 and 6. This is due to the shape of the molten pool, sketched in Fig. 3. The surface separating the weld pool from the solid region is parallel to the separating surface of the two plates and thus, to the direction the interface width is measured, the moment that the weld pool first reaches the bottom plate. This results in a very fast increase of the interface width, just after the penetration of the bottom plate has been achieved.

Figure 9 shows the dependence of the top surface concavity on the laser power and scanning speed. The top surface concavity decreases as the scanning speed increases, while it increases as the laser power does so. It can be seen that for every scanning speed, there is a critical laser power, where the top surface vanishes. This critical laser power is an increasing function of the scanning speed and it takes quite small values, ranging from 500 to $1000 \mathrm{~W}$. This critical laser power corresponds to the laser power that is sufficient for the initiation of the evaporation phase transition.

Figures 10 and 11 show the dependence of the top surface welding width on the laser power and the scanning speed in the case of butt welding. The behavior of the curves is qualitatively similar to that of the interface width, in the case of lap welding. The penetration depth for butt welding is given by the curves in Figs. 5 and 6 shifted by the thickness of the top plate.

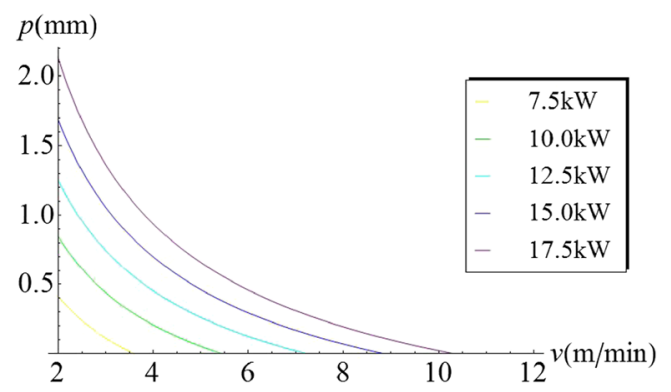

Fig. 5 The dependence of penetration depth on scanning speed for various laser powers in the case of lap welding

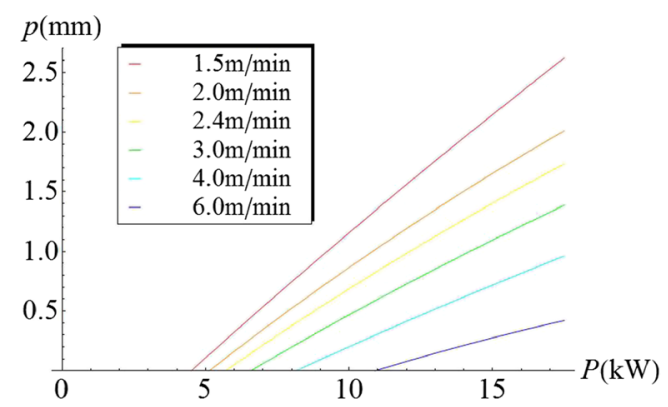

Fig. 6 The dependence of penetration depth on laser power for various scanning speeds in the case of lap welding

\section{On the energy efficiency of joining processes}

A systematic approach to the definition of the process level energy efficiency of most processes has been presented by Fysikopoulos A. et al. [18]. The energy efficiency of joining processes is defined as the ratio of the volume of the joint to the energy required for the formation of this volume:

Eef $=\frac{\text { result }}{\text { energy required for the result }}$,

where

result $=V_{\text {joint }}$.

The aforementioned definition follows the general principle that the energy efficiency should be defined as an intensive quantity and, consequently, the "result" as an extensive quantity. However, the main objective of a successful energy efficiency definition is its ability to provide comparisons of different processes, machines, or production line configurations, in order to identify the most energy efficient ones. Taking this into consideration, the main result, in a welding operation, is the successful addressing of the strength requirements; thus, the most energy efficient process is the one that achieves the given strength requirements with the smallest energy consumption. According to the above statement, the result in the energy efficiency definition should be considered proportional to the strength achieved.

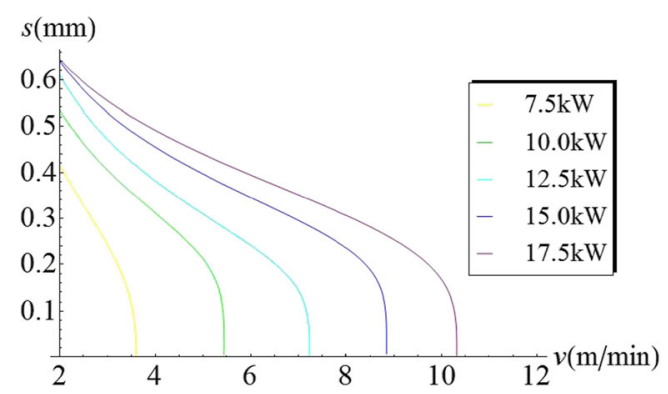

Fig. 7 The dependence of interface width on scanning speed for various laser powers in the case of lap welding 


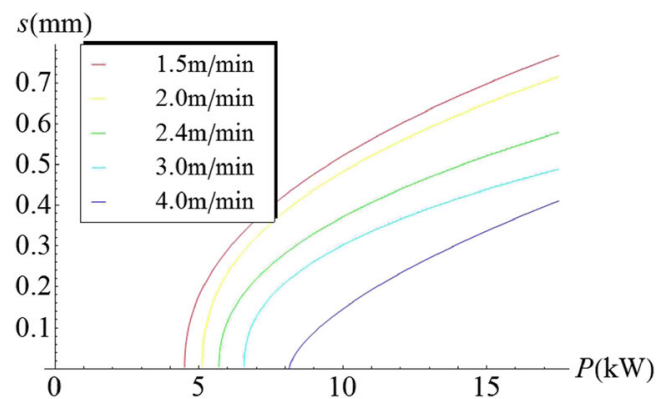

Fig. 8 The dependence of interface width on laser power for various scanning speeds in the case of lap welding

In general, an explicit relationship, between the geometric characteristics of a weld and its strength, is difficult to be determined. However, it is clear that the joint volume is not directly connected to the joint strength, as the process may have physically altered a large volume, in an inappropriate region though. The most reasonable choice of a result, being proportional to the joint strength is the area of the interface formed between the two welded pieces. Thus, the energy efficiency definition has to be modified as

$$
\text { Eef }=\frac{\text { result }}{\text { energyrequired for theresult }} \text {, }
$$

where

result $=A_{\text {interface }}$

It has to be noted that the definition of the machine tool level result for welding processes may need further considerations. For example, in lap welding, two stitches of the same length are characterized by about the same interface area; however, their strength may be quite different, depending on their shape (a different result should correspond to a circular, a polyline, or a straight stitch). Similarly, the combined result of several stitches strongly depends on their orientation, position, and shape and certainly it cannot be considered as being equal to the addition of the result for each stitch.

This study focuses on the cases of butt and lap welding. At this point, it is crucial to be stated that among others, a good weld should generate the least possible heat-affected zone

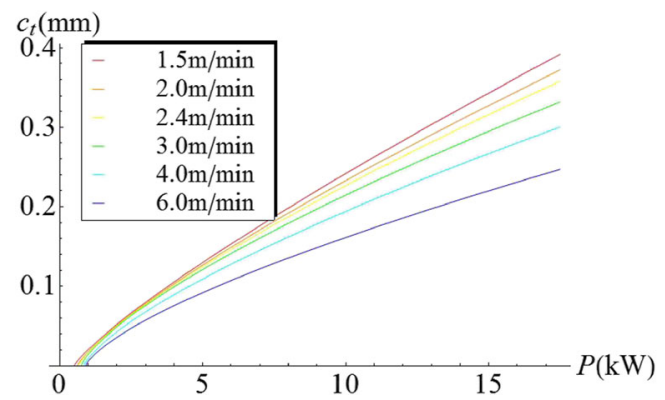

Fig. 9 The dependence of top surface concavity on laser power for various scanning speeds

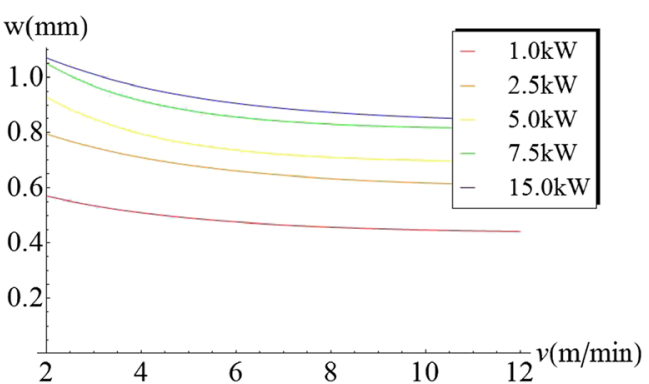

Fig. 10 The dependence of top surface welding width on scanning speed for various laser powers in the case of butt welding

(HAZ) in order to prevent the alteration of material properties, as much as possible. Some typical quality issues are depicted in Fig. 12.

The first case to be studied is the butt configuration (Fig. 13).

$\sigma=\frac{F}{p d}$

where $F$ is the tensile force, $p$ is the weld throat or penetration depth, and $d$ is the length of the weld. The average stress in a butt weld, due to shear loading $(\tau)$ (Fig. 13b), is

$\tau=\frac{F}{p d}$.

From the above equations, it is obvious that the two major factors affecting the strength of a butt weld are the penetration depth $(p)$ and the weld length $(d)$. Actually, the strength is proportional to their product, namely the area of the interface as discussed above. Consequently, the most efficient weld is the one that generates the less molten volume and HAZ and at the same time limits the effect of vaporization. Equations (4.3) and (4.4) suggest that the energy efficiency in the case of butt welding should be defined as

$E e f_{\text {butt }}=\frac{\left(p-c_{t}\right) d}{E}$

where $c_{t}$ is the top surface concavity and $E$ is the energy provided for the laser welding process.

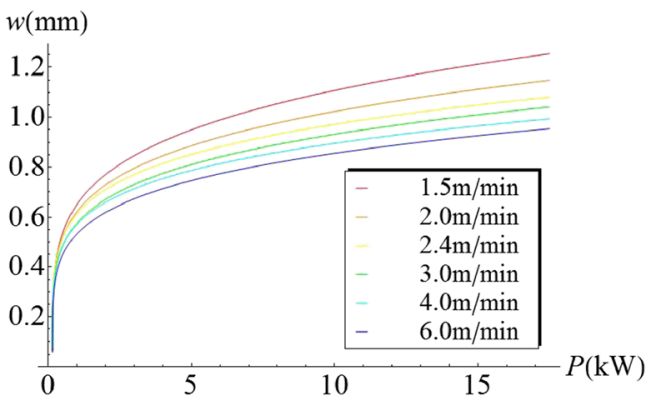

Fig. 11 The dependence of top surface welding width on laser power for various scanning speeds in the case of butt welding 
Fig. 12 Examples of various incomplete fusions in welds
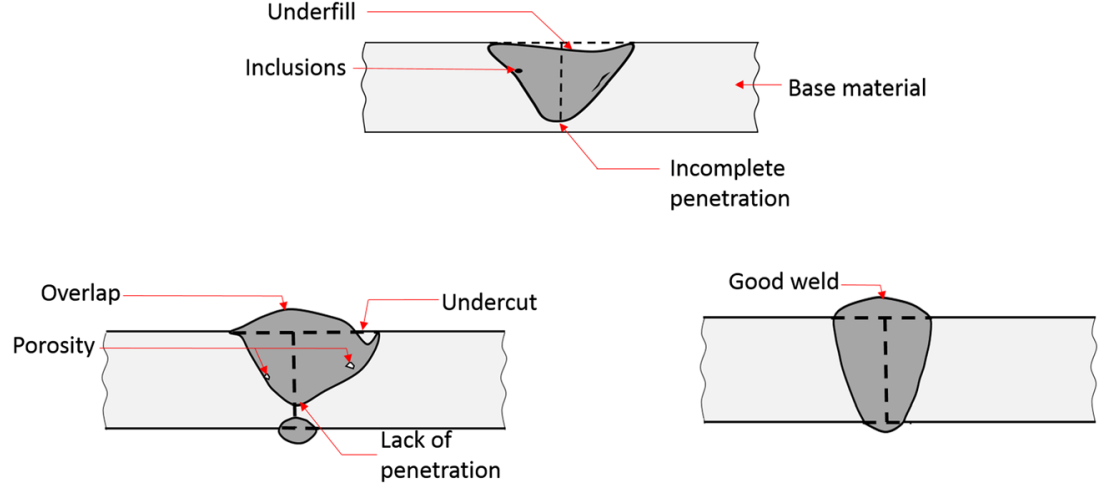

The second case is the lap welding configuration. The two factors, playing an important role on the lap joint strength, are the thickness of each material and the width of their intersection (Fig. 14) [30-32]. In case that each sheet's thickness is smaller than $5 \mathrm{~mm}$ [30] (i.e., LW applications), the result of the lap welding process can be considered equal to the intersection area as discussed above. More specifically, Eqs. (4.3) and (4.4) suggest that

$E e f_{\text {lap }}=\frac{s d}{E}$,

where $E$ is the energy provided to the process, $s$ is the welding interface width, and $d$ is the length of the weld.

\subsection{Laser welding process and the dependence of energy efficiency on process parameters}

In this section, the most energy efficient selection of parameters for the laser welding process, using butt and lap welding configuration, will be determined. In the following, different process parameters corresponding to the same result are compared. As a consequence, the laser power and the scanning speed are related, and thus, the energy efficiency will be plotted versus the laser power only. For the better interpretation of the results, an analysis of the mechanisms that absorb energy is performed. One way of dividing the absorption of energy by the material is the following:

1. Energy is absorbed for heating the material that finally will form the weld pool, to the melting temperature and for its latent heat of fusion.

2. Energy is absorbed for heating the material that finally remains solid at temperatures below the melting point.

3. Energy is absorbed for heating the material that has finally molten to temperatures below the evaporation point.

4. Energy is absorbed for the heating and the latent heats of fusion and evaporation of the material that has finally evaporated.

The first part of the absorbed energy is actually the only one that contributes to the result, since it is proportional to the weld pool volume and, consequently, it is connected to the interface area. The second and third parts correspond to the energy wasted on heat. The fourth part is a large one, since the latent heat of evaporation typically is larger than that of fusion or the energy required in order for the material to be heated up to its evaporation point. This part of the energy consumption may appear as energy loss, since it is responsible for a reduction in the weld pool volume. On the other hand, the evaporation may absorb a large amount of energy, but simultaneously it enables the laser beam to get into deeper regions of the workpiece, enlarging the weld interface area.
Fig. 13 A typical butt joint [29]Either for the tension or the compression loading (Fig. 13a), the average normal stress $(\sigma)$ is
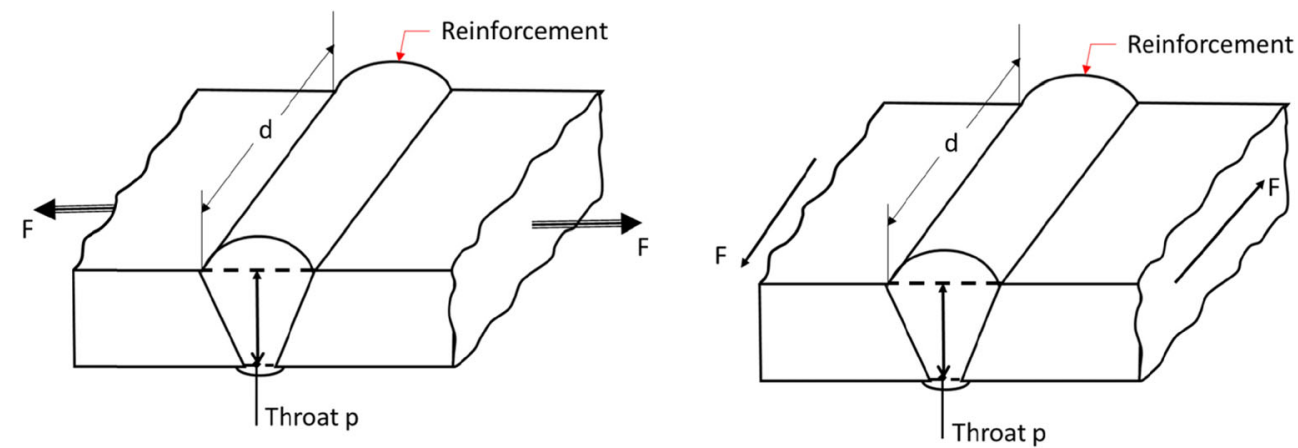
Fig. 14 Geometrical, loading, and support conditions of tensileshear loaded lap joint model [30-32]

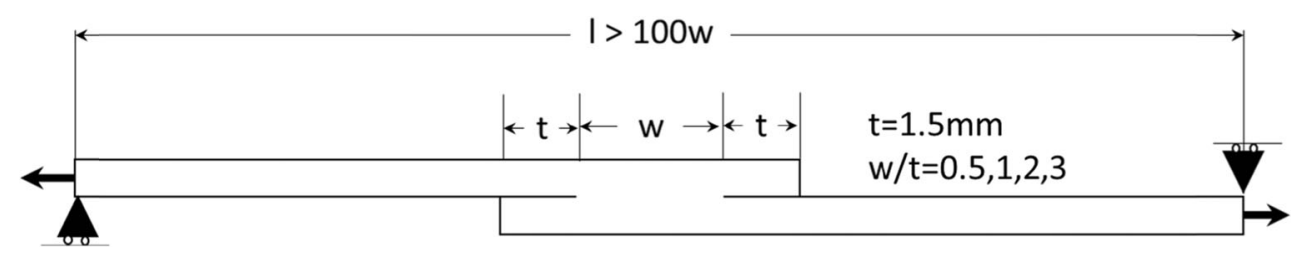

In the following sections, the parameters of Table 1, Table 2, and Table 3 are going to be used.

\subsection{Laser butt welding}

Figures 15 and 16 depict the energy efficiency as a function of laser power. For each curve, the scanning speed is fixed in such a way so as for a specific given penetration depth, in a butt welding configuration, to be achieved. The appropriate scanning speeds can be determined by finding the intersection of the curves in Fig. 5, with a horizontal line corresponding to the desired penetration depth. The figures show that the use of extra power increases the energy efficiency. This trend can be explained since the use of higher power results in less process time and, thus, less energy losses due to heat conduction. Thus, the trend "the faster the better" in terms of energy efficiency, which is also observed in other processes, e.g., [16, 18, 20], is being followed for the LW process as well.

Another important outcome of Figs. 15 and 16 is that as the desired penetration depth increases, the energy efficiency rapidly drops. This is something expected, since higher penetration depths require longer process times and the energy losses are increased due to heat conduction. The twofold effects of evaporation, which highly increase the energy consumption on the one hand and give access to deeper regions on the other, are also important. A special comment for the $0.1-\mathrm{mm}$ penetration depth should be made, since this depth is close to the conduction welding region; consequently, negligible evaporation is achieved. For this reason, all the energy induced into the workpiece is used for melting and increasing the welding region, resulting in a higher energy efficiency of the process.

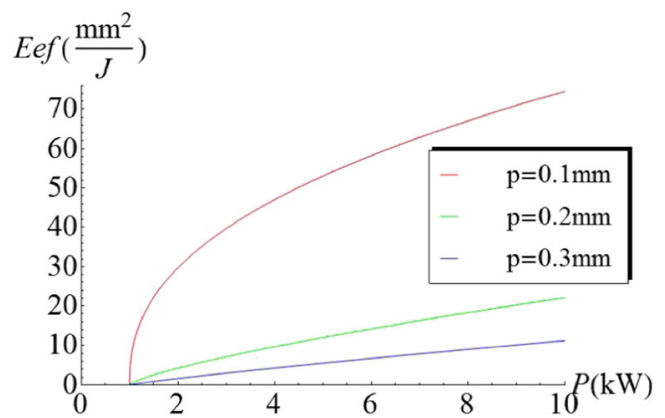

Fig. 15 Butt welding energy efficiency as a function of laser power investigating different penetration depths

\subsection{Laser lap welding}

Moving to the lap welding configuration, Fig. 17 presents the energy efficiency as a function of the laser power for different interface widths. The appropriate scanning speeds can be determined as the crossing points of the curves in Fig. 7, with a horizontal line corresponding to the desired interface width. It is observed that a higher laser power results in increased energy efficiency. This can be attributed to the same reasons as those in the butt welding case. Additionally, the smaller the welding interface is, the higher its energy efficiency. In butt welding, it was true that lower penetration corresponds to higher energy efficiency. The two trends are similar and can be attributed to the same physical reasons.

Moreover, it can be observed that for the test cases presented, the lap welding is a less efficient configuration than that of butt welding. This is expected, considering that in order for a lap weld to start being formed, the entire upper sheet should have been penetrated, while in the case of butt welding, it starts being instantly formed.

It is not simple to directly estimate the errors induced by the simplifying assumptions of the welding model in the calculation of energy efficiency. The most reliable method for the estimation of the errors is the comparison with experiments. In [28], comparison of the model with experiments shows errors in penetration depth $p$ in the order of $20 \%$. The errors in the top surface weld width $w$ are expected to be mainly affected by errors in spot size diameter and focusing and be smaller, of order 5\%. It is more difficult to estimate the error interface width $s$ in the case of lap welding. Approximating the shape of the weld pool with a conical shape, the interface width can be approximated by $s=w d_{t} / p$. Assuming canonical error

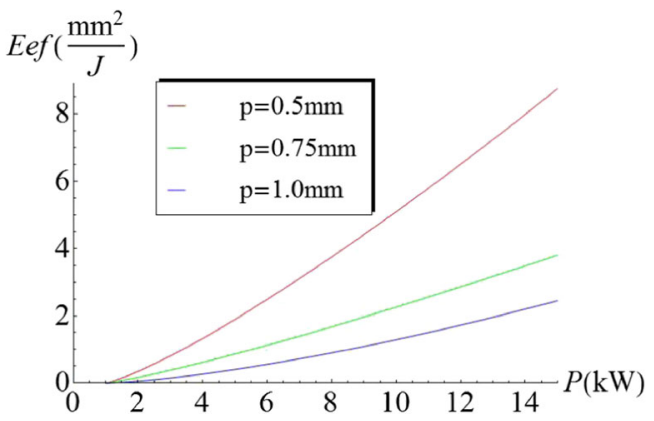

Fig. 16 Butt welding energy efficiency as a function of laser power investigating different penetration depths 


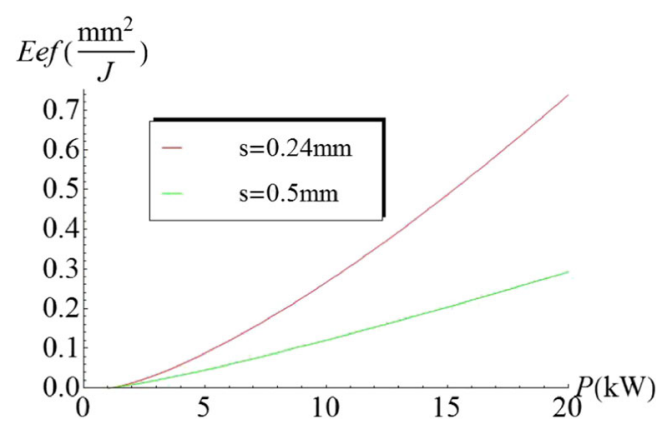

Fig. 17 Lap welding energy efficiency as a function of laser power investigating different welding interface widths

distributions in $w$ and $p$, it turns out that the errors in $s$ are in the order of $20 \%$. It has to be noted that this error may be considerably larger if the penetration depth is just larger than the top plate width $d_{t}$, since such penetration depths correspond to the steepest parts of the curves, shown in Figs. 7 and 8.

The errors in the calculated energy efficiency can be directly estimated from the formulas (4.7) and (4.8). The errors from the energy $E$ and the weld length $d$ are negligible, since these quantities are well controlled by modern laser machine tools. Therefore, in both lap and butt welding geometries, the error in energy efficiency is expected to be in the order of $20 \%$.

\section{Conclusions}

The study of the connection between the process variables and the weld pool geometry KPIs has resulted in the following conclusions:

1. Penetration begins above a critical laser power which is an increasing function of the scanning speed. Indicatively for $1 \mathrm{~mm}$ depth, the critical laser power reaches $4-10 \mathrm{~kW}$, depending on the scanning speed.

2. Similarly, penetration occurs below a critical scanning speed, which is an increasing function of the laser power. For example, for $1 \mathrm{~mm}$ depth, this critical laser power can be as low as $1 \mathrm{~m} / \mathrm{min}$, for laser powers around $5 \mathrm{~kW}$.

The study of the connection between the laser welding process variables and the energy efficiency results in the following conclusions:

1. The "result" in the energy efficiency definition should be considered proportional to the achieved strength; thus, the most reasonable choice for a result being proportional to the joint strength is the area of the interface formed between the two welded pieces.

2. The two major factors that affect the strength of a butt weld are the penetration depth and the weld length; therefore, the result is the area formed by these two factors.
3. The three factors that play an important role in the lap joint strength are each material's thickness, the weld length, and the width of the intersection. In the case of LW application, the thickness may be omitted; thus, the result of lap LW can be considered equal to the intersection area.

4. For both butt and lap LW, the energy absorbed for heating up to the melting temperature and for the latent heat of fusion of the material that has been finally molten is actually the only one that contributes to the result, since it is proportional to the weld pool volume and, consequently, it is indirectly connected to the interface area.

5. The rest are heat energy losses, except for the energy absorbed for the heating and the latent heats of fusion and evaporation of the material that has been finally evaporated. This may appear to be energy loss, since it is responsible for a reduction in the weld pool volume. On the other hand, evaporation may require the absorption of a large amount of energy, but simultaneously, the laser beam is given access to deeper regions of the workpiece.

6. The use of higher laser power increases the energy efficiency. Thus, the trend "the faster the better" in terms of energy efficiency, being observed in laser drilling [20], is also followed for the LW process.

7. It is observed that as the desired penetration depth increases in butt welding and the interface width gets higher, there is a rapid drop in the energy efficiency.

8. In general, lap welding is a less efficient configuration than that of butt welding, since more material has to be molten in order for the desired strength to be achieved.

9. For high enough scanning speeds or low enough laser powers, there is no keyhole formation; therefore, the process is actually conduction welding. In this case, energy efficiency appears to be higher than that of keyhole welding; however, it has to be noticed that the depth of the molten pool cannot exceed a certain value, making this option inapplicable when deeper penetration is required.

Acknowledgements The work reported in this paper was supported by the collaborative program entitled "Remote Laser Welding System Navigator for Eco \& Resilient Automotive Factories (RLW Navigator)," which is under the Seventh Framework Programme-FoFICT-2011.7.4: Digital factories: manufacturing design and product lifecycle management and the collaborative program entitled "Energy Efficient Process planning System ENEPLAN," which is under the Seventh Framework Program-FoF.NMP.2011-1: The Eco-Factory: cleaner and more resource-efficient production in manufacturing program.

Open Access This article is distributed under the terms of the Creative Commons Attribution 4.0 International License (http:// creativecommons.org/licenses/by/4.0/), which permits unrestricted use, distribution, and reproduction in any medium, provided you give appropriate credit to the original author(s) and the source, provide a link to the Creative Commons license, and indicate if changes were made. 


\section{References}

1. Chryssolouris $G$ (2006) Manufacturing systems: theory and practice, 2nd edn. Springer, New York ISBN:978-0-387-28431-6

2. Li L, Hong M, Schmidt M, Zhong M, Malshe A, Huis in'tVeld B, Kovalenko V (2011) Laser nano-manufacturing - state of the art and challenges. CIRP Ann Manuf Technol 60:735-755

3. De KJ, Duflou JR, Kruth J-P (2007) Monitoring of high-power $\mathrm{CO} 2$ laser cutting by means of an acoustic microphone and photodiodes. Int J Adv Manuf Technol 35:115-126

4. Ready JF, Farson DF (2001) LIA handbook of laser materials processing. Magnolia Publising, Inc., Laser Institute of America

5. Tönshoff HK, Egger R, Klocke F (1996) Environmental and safety aspects of electrophysical and electrochemical processes. CIRP Ann Manuf Technol 45(2):553-568

6. Wang P, Chen X, Pan Q, Madigan B, Long J (2016) Laser welding dissimilar materials of aluminum to steel: an overview. Int J Adv Manuf Technol. doi:10.1007/s00170-016-8725-y

7. Zhang L, Zhang G, Bai X, Ning J (2016) Effect of the process parameters on the three-dimensional shape of molten pool during full-penetration laser welding process. Int J Adv Manuf Technol 86: 1273. doi:10.1007/s00170-015-8249-x

8. Tsoukantas G, Stournaras A, Chryssolouris G (2008) Experimental investigation of remote welding with $\mathrm{CO} 2$ and $\mathrm{Nd}$ : YAG laserbased systems. J Laser Appl 20:50-58

9. Tsoukantas G, Salonitis K, Stournaras A, Stavropoulos P, Chryssolouris G (2007) On optical design limitations of generalized two-mirror remote beam delivery laser systems: the case of remote welding. Int J Adv Manuf Technol 32:932. doi:10.1007/ s00170-005-0400-7

10. Zaeh MF, Moesl J, Musiol J, Oefele F (2010) Material processing with remote technology-revolution or evolution? Phys Procedia 5: 19-33. doi:10.1016/j.phpro.2010.08.119

11. Verhaeghe G (2012) Remote laser welding for automotive seat production. Ind Laser Solut 27:6-11

12. Papakostas N, Mavrikios D, Chryssolouris G (2008) A perspective on manufacturing strategy: produce more with less. CIRP J Manuf Sci Technol 1(1):45-52

13. IEA (2007) Tracking industrial energy efficiency and CO2 emissions. France. pp 321

14. Fysikopoulos A, Papacharalampopoulos A, Pastras G, Stavropoulos P, Chryssolouris G (2013) Energy efficiency of manufacturing processes: a critical review, Procedia CIRP. 46th CIRP Conference on Manufacturing Systems - CMS 2013. Sesimbra. Portugal Procedia CIRP 7:628-633

15. Allen D, Bauer D, Bras B, Gutowski T, Murphy C, Piwonka T et al (2002) Environmentally benign manufacturing: trends in Europe, Japan, and the USA. J Manuf Sci Eng 124(4):908-920

16. Fysikopoulos A, Stavropoulos P, Salonitis K, Chryssolouris G (2012) Energy efficiency assessment of laser drilling process, (LANE 2012) Laser Assisted Net shape Engineering 7. Phys Procedia 39:776-783. doi:10.1016/j.cirp.2011.03.009
17. Gutowski T, Murphy C, Allen D, Bauer D, Bras B, Piwonka T, Sheng P, Sutherland J, Thurston D, Wolff E (2005) Environmentally benign manufacturing: observations from Japan, Europe and the United States. J Clean Prod 13(1):1-17

18. Fysikopoulos A, Pastras G, Alexopoulos T, Chryssolouris G (2014) On a generalized approach to manufacturing energy efficiency. Int J Adv Manuf Technol 73:1437-1452. doi:10.1007/s00170-0145818-3

19. Duflou JR, Sutherland JW, Dornfeld D, Herrmann C, Jeswiet J, Kara S, Hauschild M, Kellens K (2012) Towards energy and resource efficient manufacturing: a processes and systems approach. CIRP Ann Manuf Technol 61:587-609

20. Pastras G, Fysikopoulos A, Stavropoulos P, Chryssolouris G (2014a) An approach to modelling evaporation pulsed laser drilling and its energy efficiency. Int J Adv Manuf Technol 72:1227. doi:10. 1007/s00170-014-5668-Z

21. Draganescu F, Gheorghe M, Doicin CV (2003) Models of machine tool efficiency and specific consumed energy. J Mater Process Technol 141:9-15

22. Fysikopoulos A, Salonitis K, Chryssolouris G (2009) Energy efficiency of laser based manufacturing processes. Proceedings of 28th international congress on applications of lasers and electro-optics. Orlando. USA. pp 1525-1531

23. Khan MMA, Romoli L, Dini G, Fiaschi M (2011) A simplified energy based model for laser welding of ferritic stainless steels in overlap configuration. CIRP Ann Manuf Technol 60:215-218

24. Lampa C, Kaplan AFH, Powell J, Magnusson C (1997) An analytical thermodynamic model of laser welding. J Phys D Appl Phys 30:1293-1299

25. Ki H, Mohanty PS, Mazumder J (2002) Modeling of laser keyhole welding: part II. Simulation of keyhole evolution, velocity, temperature profile and experimental verification. Metall Mater Trans A 33:1831-1842

26. Shanmugam NS, Buvanashekaran G, Sankaranarayanasamy K (2013) Some studies on temperature distribution modeling of laser butt welding of AISI 304 stainless steel sheets. World Acad Sci Eng Technol 7:1088-1097

27. Salonitis K, Stavropoulos P, Fysikopoulos A, Chryssolouris G (2013) CO2 laser butt-welding of steel sandwich sheet composites. Int J Adv Manuf Technol 69:245. doi:10.1007/s00170-013-5025-7

28. Pastras G, Fysikopoulos A, Giannoulis C, Chryssolouris G (2014b) A numerical approach to modelling keyhole laser welding. Int $\mathrm{J}$ Adv Manuf Technol. doi:10.1007/s00170-013-5025-7

29. Budynas R G, Nisbett J K (2011) Shigley's mechanical engineering design. 9th ed., McGraw-Hill series in mechanical engineering. ISBN:978-0-07-352928-8

30. Lazzarin P, Berto F, Radaj D (2009) Fatigue-relevant stress field parameters of welded lap joints: pointed slit tip compared with keyhole notch. Fatigue Fract Eng Mater Struct 32:713-735

31. Radaj D, Vormwald M (2013) Advanced methods of fatigue assessment. Springer

32. Zhang S (2002) Stresses in laser-beam-welded lap joints determined by outer surface strains. Weld J:14-18 